\title{
An uncertainty approach to assessment of climate change impacts on the Zambezi River Basin
}

\author{
Charles Fant • Yohannes Gebretsadik • \\ Alyssa McCluskey $•$ Kenneth Strzepek
}

Received: 1 March 2014 / Accepted: 18 December 2014 / Published online: 18 April 2015

(C) UNU-WIDER 2015. This article is published with open access at Springerlink.com

\begin{abstract}
Many residents of the Zambezi River Valley are dependent on water-related resources. Greenhouse gas (GHG) emissions may cause a significant change to the climate in the Zambezi Basin in the future, but there is much uncertainty about the future climate state. This situation leaves policy makers at a state of urgency to prepare for these changes as well as reduce the impacts of the changes through GHG mitigation strategies. First and foremost, we must better understand the economic sectors most likely impacted and the magnitude of those impacts, given the inherent uncertainty. In this study, we present a suite of models that assess the effects of climate change on water resources for four countries in the Zambezi basin: Malawi, Mozambique, Zambia, and Zimbabwe. We use information from a large ensemble (6800) of climate scenarios for two GHG emission policies which represent a distribution of impacts on water-related sectors, considering emissions uncertainty, climate sensitivity uncertainty, and regional climate uncertainty. Two GHG mitigation scenarios are used to understand the effect of global emissions reduction on the River Basin system out to 2050. Under both climate polices, the majority of the basin will likely be drier, except for a portion in the north around Malawi and northern Zambia. Three Key Performance Indicators are used-flood occurrence, unmet irrigation demand, and hydropower generation - to understand the impact channels of climate change effects on the four countries. We find that floods are likely to be worse in Mozambique, irrigation demands are likely to be unmet in Mozambique and Zimbabwe, and hydropower generation is likely to be reduced in Zambia. We also find that
\end{abstract}

This article is part of a Special Issue on "Climate Change and the Zambezi River Valley" edited by Finn Tarp, James Juana, and Philip Ward.

Electronic supplementary material The online version of this article (doi:10.1007/s10584-014-1314-x) contains supplementary material, which is available to authorized users.

C. Fant $\cdot$ K. Strzepek $(\bowtie)$

Joint Program on the Science and Policy of Global Change, Massachusetts Institute of Technology,

Cambridge, MA, USA

e-mail: strzepek@mit.edu

Y. Gebretsadik

Civil, Environmental, and Architectural Engineering, University of Colorado, Boulder, CO, USA

A. McCluskey

Mortenson Center in Engineering for Developing Communities (MCEDC), University of Colorado, Boulder, CO, USA 
the range of possible impacts is much larger under an unconstrained GHG emissions case than under a strict mitigation strategy, suggesting that GHG mitigation would reduce uncertainties about the future climate state, reducing the risks of extreme changes as compared to the unconstrained emissions case.

\section{Introduction}

Climate change may pose substantial risk to Africa's water resources (IPCC 2007) while most Africa nations have contributed almost nothing to global emissions. This is compounded by the far greater exposure of its economies to natural climatic variation. The most daunting truth of our current understanding of future climate is the inherent uncertainty of the changes. While mitigating greenhouse gases (GHG) may alleviate these effects, including the uncertainty, it will likely require an expensive and complicated global effort. Furthermore, African policymakers have limited quantifiable information to leverage their efforts to negotiate more stringent mitigation targets.

Understanding the effects of climate change on water resource systems under uncertainty has been studied extensively in the last few decades (e.g., Dessai and Hulme 2007; Brown and Wilby 2012; Haasnoot and Middelkoop 2012; Arora and Boer 2001; Haasnoot et al. 2013) and understanding decision making under uncertainty has also been addressed (e.g., Kwadijk et al. 2010; Wilby and Keenan 2012). Arora and Boer (2001) provides a comprehensive review of the types of approaches used to answer this type of question. Two of these methods are: (i) a climate sensitivity analysis on existing or planned infrastructure using a wide range of future climate possibilities (e.g., Kurukulasuriya et al. 2006; Wilks 1992); or (ii) use of select Global Circulation Models (GCMs) from the Coupled Model Intercomparison Project (CMIP) used in the Intergovernmental Panel for Climate Change (IPCC) fourth Assessment Reports applied directly to assess the impacts of climate change (e.g., Liu et al. 2013; Arndt et al. 2010, World Bank 2009; Immerzeel 2008). Method (i) is effective at understanding the conditions that would cause a system to fail, but the climate scenarios have no direct ties to realistic effects of GHGs on climate, although this can be updated after the fact (e.g., Prudhomme et al. 2010; Brown and Wilby 2012). On the other hand, method (ii) is effective at modeling the effect of GHG emissions but not effective at representing the full range of possible climate changes, as pointed out by Brown and Wilby (2012). In this study, we combine methods (i) and (ii) on the front end, essentially aimed to quantify the impacts on biophysical measures - surface water supply, flooding events, and hydropower generation - of the Zambezi Basin countries using information from a large pool (6800) of climate mean projections, similar to method (i), which are based on the majority (17) of the IPCC AR4 GCMs, similar to method (ii). We do this for two mitigation strategies - strict greenhouse gas mitigation and business as usual-which consider the inherent uncertainties in emissions, climate sensitivity, and regional changes in climate (Schlosser et al. 2013). We do not consider adaptation measures, which will likely be effective at dealing with these climate impacts. Instead, we attempt to identify sectors and countries most likely to be effected by climate changes, therefore detecting where resources would be most effectively spent. We also do not propose an adaptive plan forward, as in Haasnoot et al. (2013). We focus the uncertainty analysis on the effect of the change in future mean climate state, and do not consider other uncertainties, of which there are many, such as the past or present environment, biophysical modeling techniques, power demands, management decisions, etc. Dessai and Hulme (2007) perform a similar analysis on the East of England and find that regional climate change is the largest source of uncertainty, although this analysis is only driven by 2 GCMs. 
The Zambezi River Basin in southern Africa provides a problem area suitable for this type of study both because of the hydrologic and agricultural importance for the people who live in the area (World Bank 2010; Hassan 2010; Collier et al. 2008), i.e., the region is vulnerable to changes in climate, and due to previous studies concluding that the impact of climate change will likely be significant (Arora and Boer 2001; de Wit and Stankiewicz 2006; Lobell et al. 2008; World Bank 2010). IPCC (2001) documents earlier work on the Zambezi, where these studies claim the basin will experience the greatest decrease in runoff as compared to the rest of Africa (e.g., Arnell 1999). De Wit and Stankiewicz (2006) conclude that the majority of the basin will be drier, about a $10 \%$ reduction in precipitation, by 2100 ; although a small section in the north around Malawi and northern Zambia will likely experience increased precipitation. The study also notes that a $10 \%$ reduction in precipitation would likely result in a much larger reduction in runoff, closer to $50 \%$ in the Zambezi. Arora and Boer (2001) estimate that the Zambezi River, evaluated at the delta in Mozambique, will experience a total reduction in discharge of about $39 \%$ in 2100. Although, it should be noted that Mazvimavi and Wolski (2006) find recent observed changes in the Zambezi river flows can be explained by a cyclical pattern rather than a trend.

\section{Material and methods}

The study presented here is part of a larger integrated framework that includes work from many others as illustrated in figure in the supplemental material (Online Resource 1) specifically, this study is dependent on: (1) producing the climate scenarios (Schlosser and Strzepek 2014), used as input in this study, and (2) determining the effect on the economy (Arndt et al. 2014), which uses the output from this study and introduces an adaptive economy in equilibrium, in order to understand the economic impacts. Many of the choices made here were directed by these front-end and back-end pieces. This section provides descriptions of the following: the climate scenarios in sub-section 2.1; the rainfall-runoff model in sub-section 2.2, which uses input from the climate scenarios and provides input for the water resources model; the crop model in sub-section 2.3, which also uses the climate as input and provides input into the water resources model; and the water resources model in sub-section 2.4, which uses input from the climate - reservoir evaporation - as well as the rainfall-runoff model and crop model to produce indicators used to illustrate the climate change impacts.

\subsection{Climate scenarios}

For the historical scenario, monthly near-surface temperature and precipitation data a a halfdegree by half-degree spatial scale were obtained from the Climatic Research Unit (CRU) of East Anglia (Mitchell and Jones 2005) for the years from 1951 to 1990. Daily climate data, which spans the same years as the monthly data, is required for the crop modeling. These data were sourced from the Land Surface Hydrology Research Group at Princeton University (Sheffield et al. 2006) in August 2011. These data are at a scale of 1-degree by 1-degree and are corrected to match the CRU mean monthly data.

The future climate scenarios used in this study are based on GCM ensemble results from the CMIP-3, but are expanded to represent a larger range of possible outcomes following that of previous work (Schlosser et al. 2013). The MIT Integrated Global Systems Model (IGSM; Reilly et al. 2012) developed near-surface temperature and precipitation projections to 2050 at the zonal spatial scale (Webster et al. 2012). A Taylor expansion technique, described by Schlosser et al. (2013), was used to expand from the zonal level of detail in the longitudinal 
direction. This transformation requires the construction of climate-change pattern kernels, which vary through time as global temperature changes. The full ensemble of climate change projections is produced through a numerical hybridization of the IGSM zonal trends with pattern kernels of regional climate change from the IPCC AR4 models. Although the method used the A2 emissions scenario, Schlosser et al. (2013) has proven that this made no significant difference in the climate patterns. This ensemble of future climate projections is called "hybrid frequency distributions" (HFDs). Using this framework, 6800 climate projections are produced for each of the five $\mathrm{CO}_{2}$ emissions policy scenarios (scenarios from Webster et al. 2012); although, we only use the two extreme emission policy cases to understand the policy effect of either: no mitigation, termed as "unconstrained $\mathrm{CO}_{2}$ emissions" (UCE), where no policy actions are taken to limit greenhouse gas emissions; or strict mitigation, termed as "Level 1 Stabilization" (L1S), with restraints on global emissions to prevent greenhouse gas concentrations from exceeding $560 \mathrm{ppm} \mathrm{CO}_{2}$ equivalent. In order to reach a reasonable computation time for all subsequent modeling, the number of projections was reduced using a Gaussian Quadrature as described in Arndt et al. (2014), which reduced the climate projection pool to 421 statistically significant scenarios for UCE and 399 for L1S. The changes in climate were calculated as changes in precipitation and near-surface temperature of the future compared to the modeled history, a seasonal (i.e., separately for each month) 11-year moving average was applied, and these smoothed changes in climate were then added to the historical data on a monthly basis. This technique maintains the inter-annual variability of both climate variables as well as the daily distribution of precipitation by adding the changes proportionally by daily intensities. Note that this technique only changes the long-term mean climate for the future scenarios. This method does limit us to studying the impact of the mean change in climate on the system, rather than the impact of changes in inter-annual variability, which may be significant. We do this to avoid introducing more uncertainty into the analysis, as it is well known that GCMs are better at reproducing historical climate mean than variability (Blöschl et al. 2007), especially for precipitation. We do, however, preserve persistent shifts in the season, e.g., a wetter rainy season and drier dry season. Also, addressing the issue of changes in variability is a topic we plan to address in future work. This would likely involve a more complicated bias correction procedure that takes advantage of the CMIP-5 model output, which is more spatially and temporally detailed.

Future climate changes from 2011 to 2050 are used in the modeling efforts described in the remainder of this section.

\subsection{Runoff model}

Runoff modeling converts the climate changes into changes in surface water availability important for the water resource model. Surface water runoff was modeled with the rainfallrunoff model CLIRUN-II (as used in Strzepek et al. 2011), the latest available model in a family of hydrologic models developed specifically for the analysis of the impact of climate change on runoff, first proposed by Kaczmarek (1993). CLIRUN-II models runoff with a lumped watershed (i.e., each watershed is modeled spatially homogeneous) defined by climate inputs and soil characteristics, simulating runoff at a gauged location at the mouth of the catchment on a monthly time-step.

CLIRUN-II has adopted a two-layer approach following the framework of the SIXPAR hydrologic model (Gupta and Sorooshian 1983, 1985). An extension to CLIRUN-II, "CLIRUN-II-WET", was developed to better model the losses caused by the wetland areas. The model simulates wetland hydrology based on the work of Sutcliffe and Park (Sutcliffe and Parks 1987) for the White Nile Sudd wetland, Yates and Strzepek (1998) for the White Nile 
wetlands generally, and Kashaigili et al. (2006) for the Usangu Plains wetlands in Tanzania. The wetland area is modeled in each catchment using a reservoir-based hydrologic response, where the estimated ET, calculated using the Modified Hargreaves Equation, Droogers and Allen (2002), and runoff at the catchment is used to simulate the water balance, including inflow, outflow and storage.

A unique conditional calibration procedure was used to determine 7 unique shape parameters that characterize each of the 29 catchments. The shape parameters include soil layer depths, coefficients for baseflow and surface flow velocities, and coefficients that govern the transfer of water between, into, and out of the soil layers. The calibration procedure optimizes via a pattern search algorithm developed by MATLAB minimizing the sum of square errors of the simulated and observed runoff. The observed runoff was provided by personnel from the World Bank through personal communication. This is the same runoff used to calibrate the model used in World Bank (2010). CLIRUN-II-WET was calibrated over the period 19711980 and validated over 1981-1990. The calibration achieved a coefficient of determination, based on monthly runoff, of 0.9 or greater for all catchments.

\subsection{Crop model}

The purpose of the following analysis is to assess the changes in crop yields (to be used in economic models in subsequent work to assess investment opportunity), and to estimate changes in irrigation demands to feed into the water resource model. Nine crops were chosen to represent the agriculture sector across all four countries. The 9 crops are maize, wheat, cassava, horticulture (i.e., a generic vegetable crop), tobacco, cotton, sugarcane, and tea. A variation of the CROPWAT model (Smith 1992), termed "CliCrop" (as described in Fant et al. 2012) was used to estimate the variability of the impact on crop water requirement and rainfed crop yields caused by the range of climate projections present in the HFDs.

The effects of climate on crop production are modeled by estimating water stress on crops. Water stress is related to the estimate of evapotranspiration (ET), and more specifically, the extent by which the actual ET (AET) falls short of the crop demand ET (DET). In CliCrop, the crop water deficit, used to estimate irrigation demand is the difference between DET and AET, summed over the crop season. Actual ET is calculated as a function of precipitation, temperature, PET, soil moisture, root depth, crop type, and atmospheric $\mathrm{CO}_{2}$ concentration. This calculation is done each day, for each soil layer. The model uses a daily form of the Modified Hargreaves equation to calculate PET (Farmer et al. 2011). CliCrop uses the soil properties and precipitation amount to calculate the infiltration using a version of the USDA Curve Number method (USBR 1993). Soil moisture below the surface is calculated using a bucket-type scheme similar to the method used in the SWAT model (Neitsch et al. 2005), details are given in Fant et al. (2012). Crop specific parameters similar to the ones used in CROPWAT are used in this calculation, as well as in the calculation of the daily ET crop demand. The atmospheric $\mathrm{CO}_{2}$ concentration affects the daily ET crop demand, which follows the methods explained in Rosenzweig and Iglesias (1998) but the effects of $\mathrm{CO}_{2}$ fertilization on nutrients and growth are not taken into account in CliCrop. The crop parameters are adjusted from year to year using methods developed by Allen et al. (1998)-adjusting crop ET demand-and Wahaj and Maraux (2007)-adjusting crop stage durations, which estimate the local crop's reaction to deviations from "average" climate conditions.

Water withdrawn for irrigation includes irrigation scheme efficiency dependent on the irrigation technology, as well as conveyance efficiency, which accounts for the water loss transporting the water from the source to the field. CliCrop estimates the amount of water required by the crop at the roots, which does not account for either of these efficiencies. Therefore, CliCrop was validated for yield and irrigation demands in the U.S., where data is 
substantially more reliable than in the Zambezi Basin. We found that CliCrop is able to capture the inter-annual variability for both yield and irrigation demand (details in Fant et al. (2012)). For this reason, and to account for both types of irrigation efficiencies, we scale the modeled historical mean irrigation demands by the historical mean values used in World Bank (2010). In doing this, we assume that both irrigation efficiencies remain the same in the future.

\subsection{Water resource system model}

The water resource modeling in this study attempts to simulate the sequence of existing and planned reservoir activity and demand nodes along the system. The focus of this modeling effort is on three main indicators of future impact: assessing possible changes in flood risks, the operation of major hydropower plants, both existing and planned, and maintaining agricultural production, taking into account changing irrigation demands over time. Three demand types, or nodes, are modeled throughout the system, which are in competition for water dependent on the sequence (upstream/downstream). The node types are municipal and industrial (M\&I) water use, hydropower generation, and irrigation withdrawal. M\&I demands increase over time, consistent with projections used in the World Bank Economics of Adaptation to Climate Change study (EACC; World Bank 2009). Hydropower production is calculated for existing and planned projects based on expected investment and construction schedule from World Bank (2010). The existing and planned irrigation infrastructure changes over time are also obtained from World Bank (2010). The Zambezi Basin water resources are modeled on a monthly time-step using the Water Evaluation And Planning (WEAP) model (Sieber and Purkey 2007), a well-established river basin system modeling software.

The WEAP model used in our study was validated against the HEC-3 river basin model used in the World Bank (2010) study. The average hydropower results over the historical period, 1970-2000, show system-wide hydropower to be $90 \%$ of historical generation. Considering that we use modeled runoff, wetland losses, and irrigation demand, all biased from observation, this model was considered acceptable for this study.

\section{Results and discussion}

The distributions of changes in climate - temperature and precipitation-are shown in Fig. 1 as a mean of the four countries in the region. Changes in climate, in this case, are defined as changes from the 1981-1990 model mean to the 2041-2050 mean of each climate scenario result. The 10th, 50th, and 90th percentile points on the distribution for each of the four countries are also shown in Fig. 1 to show how changes vary for each country. In general, the majority of the basin is projected to be drier except for the northern portion of Zambia and most of Malawi, which are expected to be wetter. These changes in climate are consistent with the composite of 21 leading GCMs shown in De Wit and Stankiewicz et al. (2006). The L1S scenario is projected to result in less of a median temperature increase than UCE by about 0.5 C. The median change in precipitation is projected to be close to no change basin-wide for both policy cases, although the L1S scenario is more likely to result in slightly less precipitation, for all countries except Mozambique, where there is little difference in the median. The most striking difference in the distributions of the two policy cases for both temperature and precipitation is the range of the extremes, suggesting that GHG reduction policies are likely to reduce the uncertainty of the future climate state, even by the 2040s. We next compare these changes in climate to the natural inter-annual variability of the baseline scenario, 1951-1990. We find that the changes in temperature are large compared to the historical variation, where 


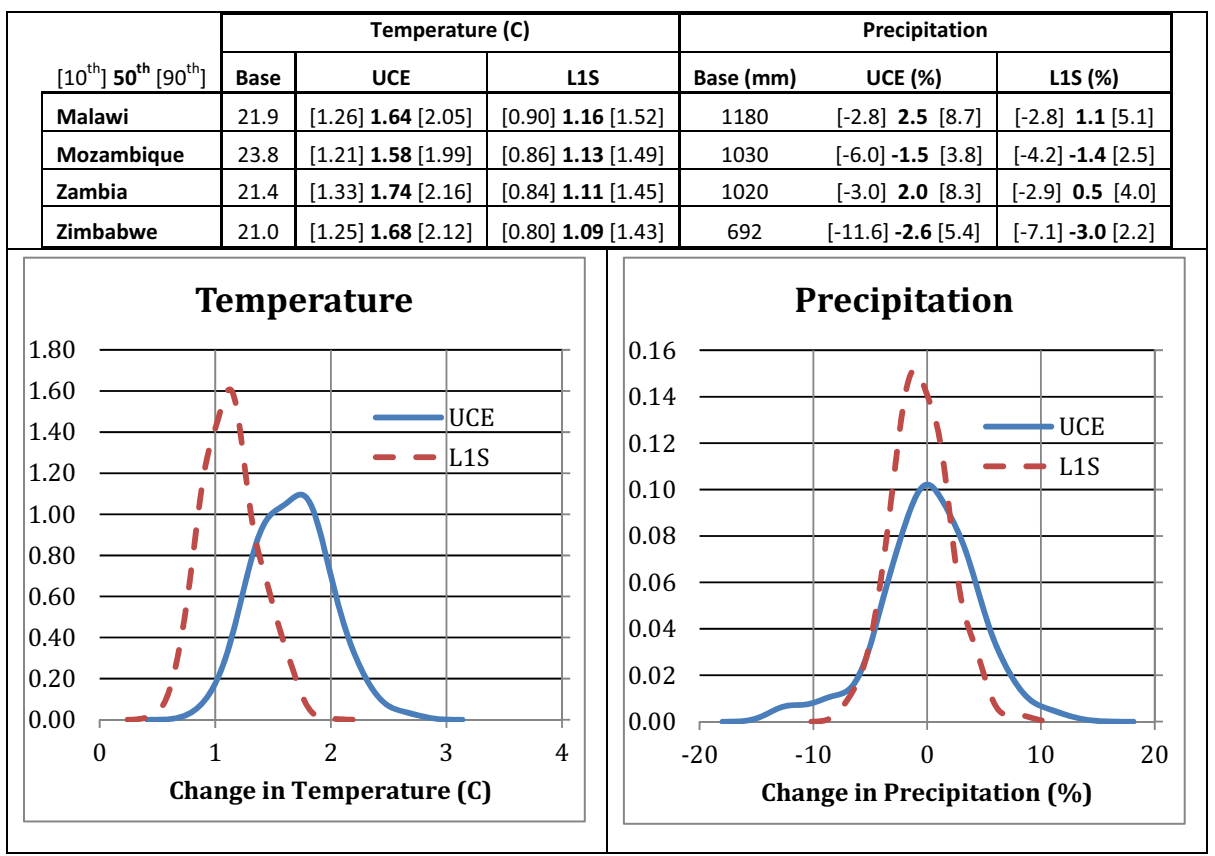

Fig. 1 (top) Values of the historical climate, calculated over 1951-1990, and the [10th] 50th [90th] percentiles in the distribution across climate scenarios of changes in temperature and precipitation in the 2041-2050 mean compared to the 1991-2000 for each of the four countries and the two policy cases. Distribution of mean changes in temperature (bottom left) and changes in precipitation (bottom right) comparing the 2041-2050 mean of each climate scenario to the 1991-2000 model mean for the four Zambezi Countries for both policy cases

the 10th and 90th percentiles in the baseline are about $+/-0.4$ from the mean for all four countries. On the other hand, future changes in precipitation are smaller than interannual variability. The difference in both the 10th and 90th percentile as compared to the mean ranges from about $+/-15 \%$ in Malawi, Mozambique, and Zambia, and $+/$ $-28 \%$ in Zimbabwe.

The percent change in mean annual runoff, aggregated from 29 basins to 5 major basins, is shown in Fig. 2. In this figure, the baseline mean annual runoff is shown as a proxy for the hydrologic significance of each basin. Also the 10th and 90th percentiles of the modeled historical - 1951 to 1990 - is shown as a difference from the modeled historical mean and is used as a proxy for the significance in the climate scenario results. The Upper Zambezi, Kafue, and Lower Zambezi are likely to be have at least a $5 \%$ decrease in runoff by the 2040s for over half of the scenarios under the UCE case. The Upper Zambezi is less likely to have a $5 \%$ decrease in runoff under the L1S scenario-with a likelihood of about $40 \%$ - but the Kafue and Lower Zambezi are more likely to have the same decrease, with about a $60 \%$ likelihood. The Zambezi at Cahora Bassa and Shire River are more likely to have an increase in runoff by the 2040 s under both policy cases, with a likelihood of a $5 \%$ decrease in runoff at around 17 and $6 \%$ probability, respectively, under UCE and $23 \%$ and $12 \%$ probability, respectively, under L1S. Although most of the basins are more likely to be drier under UCE, L1S results in less uncertainty as shown in the range of the distributions. We also note that the inter-annual variability of the historical runoff, as shown by the 10th and 90th percentiles, is close to the range of the climate ensemble distributions, and often larger. But, of course, the ensemble 


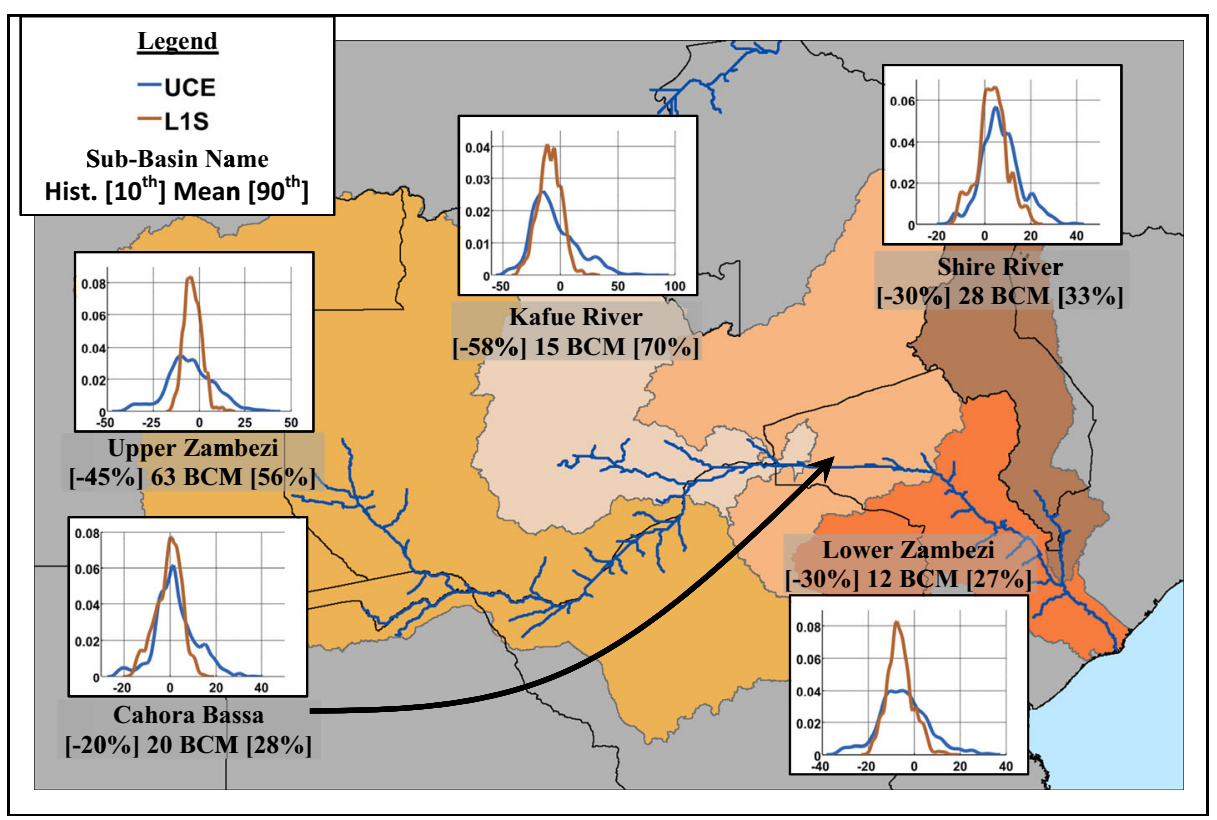

Fig. 2 Climate scenario distribution results of the predicted percent change in runoff for the five major subbasins of the Zambezi River Valley under both policy cases-Unconstrained Emissions (UCE) in blue and Level 1 Stabilization (L1S) in red. The baseline (1951-1990) mean runoff in Billion Cubic Meters (BCM) and the percent different between the mean and both the 10th and 90th percentiles are shown below the basin name ([10th] mean [90th])

distributions represent a shift in the 10-year mean with an unknown inter-annual variability around that mean.

Next, we present the three major indicators, which are used to demonstrate the changes in projected impacts to the hydrologic system: occurrence of extreme value maximum monthly runoff, used as an indicator for flood event occurrence; hydropower generation changes; and changes to unmet irrigation demands.

Flooding risk is typically modeled at a daily or sub-daily level, while we are limited by the nature of this analysis to monthly runoff changes. In that case, these results are likely underestimating flood risk and correspond specifically to large-scale flooding events-floods causing river inundation - rather than local flash flooding events. Using an extreme value distribution fitting, we make claims on the recurrence of damaging flood events. We do this by fitting runoff over the period, 1951 to 2000 , estimating the recurrence interval of high runoff events. We then use the fitted parameters from the historical fit for the future runoff to calculate future recurrence intervals. Figure 3 shows the occurrence of high-damage flood events, greater than the 50-year event intensity, as a mean over all basins within the country. We did not find changes to flood occurrence in Malawi or Zimbabwe. Considering that, on average, about 1 high-damage flood event occurs in the 50-year base scenario, Mozambique and Zambia are more likely, based on this analysis, to have a significant increase in highdamage flood events in the future under the UCE case than the L1S case. Again, this analysis is limited by the fact that we are only considering changes in the monthly mean climate, not changes in inter-annual variability. These results are primarily driven by persistent seasonal changes in precipitation, where precipitation in high-runoff months increases, while precipitation in low-rainfall months decreases. 


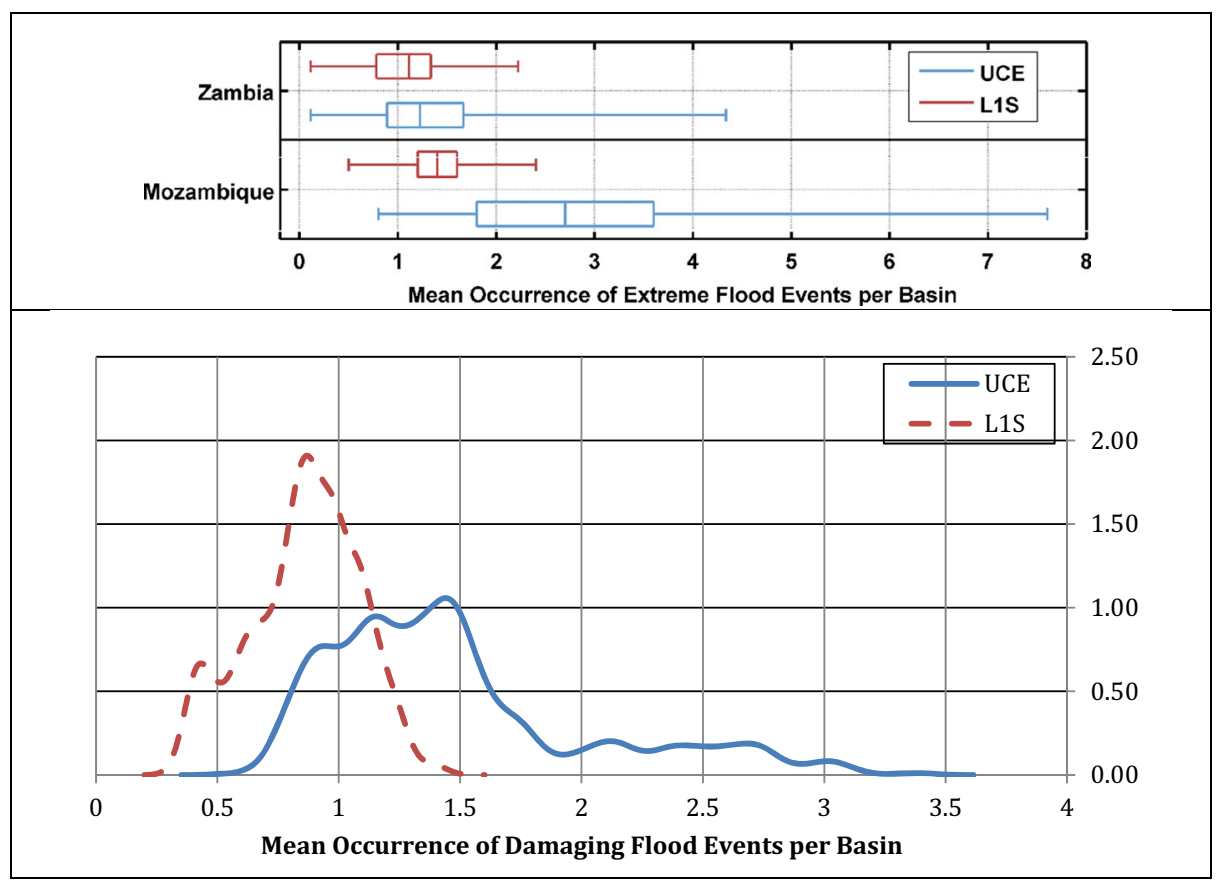

Fig. 3 (top) Distribution of the changes in the occurrence of flood events per basin greater than the 50-year event for Zambia, Mozambique, and Malawi for the future climates of both mitigation scenarios-Unconstrained Emissions (UCE) in blue and Level 1 Stabilization (L1S) in red-for Zimbabwe and Mozambique for the modeled future 2040s as compared to the modeled historical 1990s. (bottom) Kernel Smoothing of the distribution of the same value aggregated for the four Zambezi countries

The impacts on irrigation availability are presented as the changes in shortage volume, where the shortage volume is defined as the volume of water delivered to the irrigation node in the WEAP model subtracted from the volume of water demanded by the irrigation node. In the upstream countries, Malawi and Zambia, the irrigation shortage remained insignificant in almost all of the scenarios (i.e., the amount of water delivered equaled the amount of water demanded). Due to mostly increasing predicted runoff in Malawi, and very small irrigation shortages in the base scenario, the impact of climate change on irrigated agriculture is expected to be small. In Zambia, the effect on irrigation demands is also expected to be small which is mostly attributed to the spatial distribution of irrigation schemes (i.e., areas with more irrigation demands are drying less than areas with more hydropower generation capacity). In contrast, irrigation shortage in Zimbabwe and Mozambique is affected negatively by the predicted drying. Figure 4 shows the distributions for Zimbabwe and Mozambique, where here an increase infers a negative impact. We do not show Malawi and Zambia because irrigation demands were met in all future cases resulting in no unmet irrigation demand. Again, we find that the UCE policy case would result in a larger range of uncertainty than L1S. We also find that the median for UCE would result in more unmet irrigation demand for Zimbabwe, Mozambique and the sum of the four Zambezi countries.

The impacts on hydropower generation by country are presented in Fig. 5. The hydropower plants shared by countries were split in accordance with the way they are realistically shared between countries, as is detailed in World Bank (2010). Again, the UCE case predicts more of a change from the baseline than the L1S. Malawi is the only country where a positive impact is 


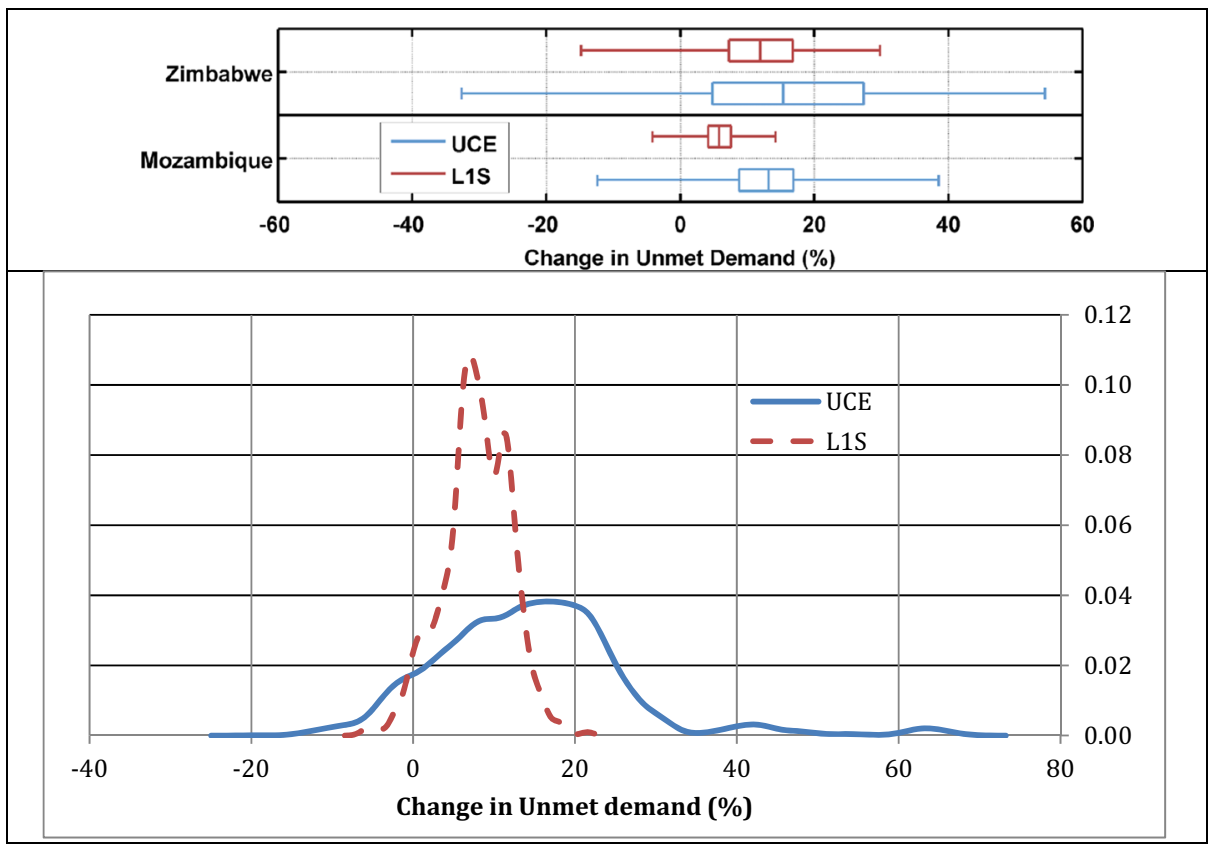

Fig. 4 (top) Distribution of the changes in unmet irrigation demand for Zimbabwe and Mozambique for the future climates of both mitigation scenarios-Unconstrained Emissions (UCE) and Level 1 Stabilization (L1S) - for Zimbabwe and Mozambique for the modeled future 2040s as compared to the modeled historical 1990s. (bottom) Kernel Smoothing of the distribution of the same value aggregated for the four Zambezi countries

predicted in the majority of scenarios. Alternatively, in Zambia, hydropower generation is predicted to decrease in most future climates. With runoff decreasing in Zambia in the west, upstream of the majority of the hydropower plants, these results are expected. In Zimbabwe, where hydropower is generated downstream of Zambia, hydropower production is predicted to decrease slightly in most of the scenarios, suggesting that no significant impact would be expected. In Mozambique, where there are a few large downstream hydropower plants, there is expected to be no significant change in energy production. The reservoirs behind these hydropower plants are large, with significant storage, and they are downstream of a large portion of the Zambezi Basin dampening the resulting inflow changes. Further, the hydropower demand is small in proportion to the generating capacity. If power trade with neighboring countries were considered, these results might change since Mozambique would likely export excess power when the electricity price is high. With these results, we can see that the upstream hydropower plants located in Zambia and Malawi are much more sensitive to changes in local runoff, while the downstream plants located in Zimbabwe and Mozambique are less sensitive, since they have the luxury of a large contributing area-where a combination of increasing and decreasing runoff is expected.

\section{Conclusions}

Based on this study of the Zambezi valley system, the future climate is likely to be drier in the basin as a whole, although there is a tendency toward a wetter climate in a small section in the 


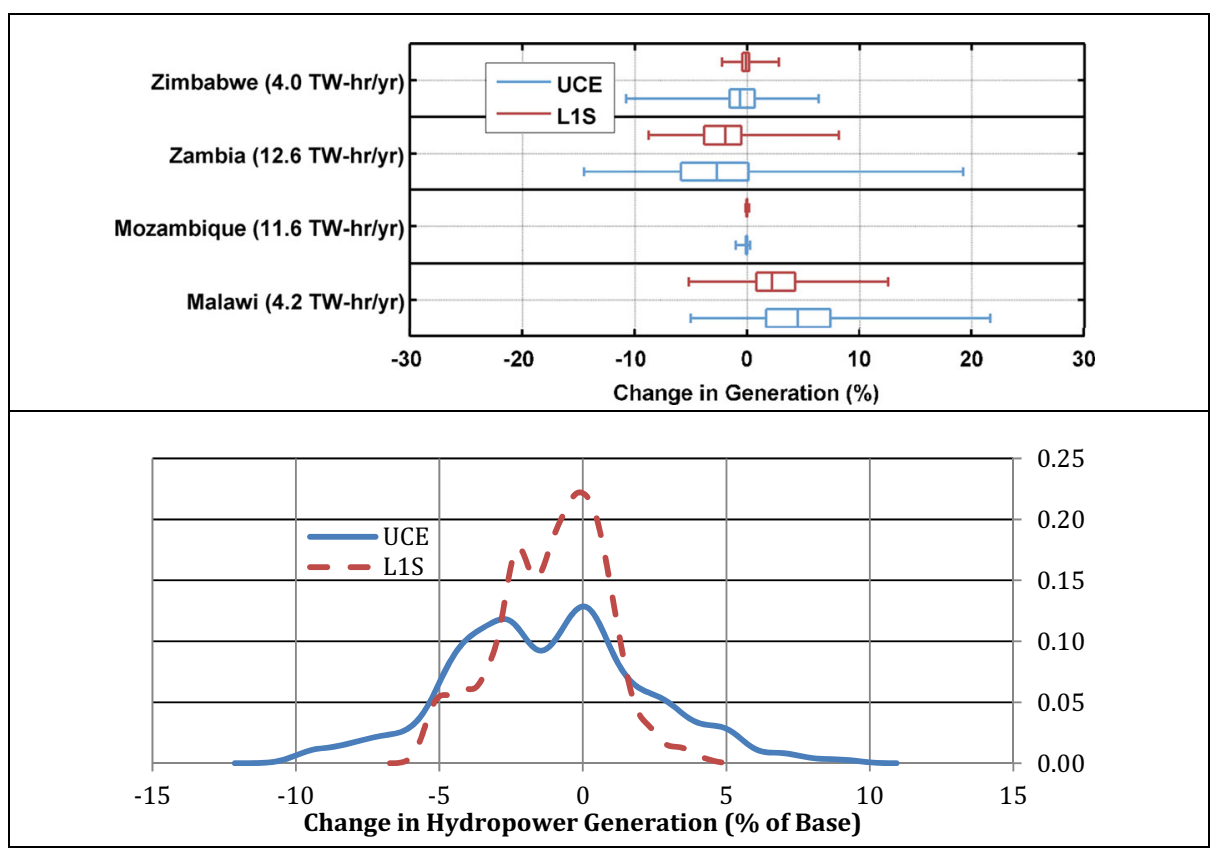

Fig. 5 The top figure shows the distribution of changes in hydropower generation for the four countries for both policy cases. The base annual generation is shown in parenthesis. The bottom figure shows the distribution of the aggregate change in hydropower generation across future climates for both policy cases

north. We have quantified, with a frequency distribution of projected climates for two policy cases, how climate change will likely reduce surface water availability basin-wide. And finally, using a water resource system model, derived frequency distributions of possible impacts on economically significant outcomes - namely, changes in flood occurrence probability, hydropower generation, and unmet irrigation demand - are generated. The UCE policy case results in more uncertainty than the L1S, which is largely a result of the climate scenario distribution. More specifically, we have found that Malawi is the least sensitive to climate change. Alternatively, Zambia is predicted to experience losses in terms of hydropower generation, caused mostly by expected decreases in runoff in the west, as well as upstream irrigation demands. In Zimbabwe, the mean of the distribution of hydropower generation suggests that it is not likely to be impacted, but there is about an equal chance of increase as decrease. In contrast, the future irrigation investments could be at risk of water shortage. The impacts to Mozambique hydropower is likely to be mild because it has the benefit of a large contributing area with varying types of impact (both increases and decreases in surface water availability), but large-scale, high-damage flood events will likely happen more often, especially under UCE policy, and irrigation demands are likely to be unmet. When comparing these results with historical inter-annual variability, we find that the range of future scenarios is rarely larger than what these countries have experienced over the historical period. So, although these impacts are likely to be costly, they should be manageable, at least to 2050 .

An obvious next step is to assess adaptation options for the region that could alleviate the cost of these likely effects. In this study we model all actors in the system behaving as they do now. We leave adaptation option assessment to future research. In this regard, we do find that these countries will likely experience different impact channels in the future, although there is 
some overlap. In presenting these indicators for each country, we have also presented the aggregate value over the four countries. In all cases, as one would expect, the aggregate effect is less severe than the effect on the country with the largest adverse effect. This implies that cooperation and trade among these countries may be more beneficial in the near future. Of course, we do not pretend to represent, in this study, the complicated economics involved in proving this to be the case. Instead, we leave that to future research as well.

As mentioned, climate changes after 2050 are generally predicted to be more drastic. Changes in the latter part of the century might be useful in future planning. Also, since all of the impacts are discussed here as changes from a baseline scenario, introducing inter-annual variability, including changes in global climatic phenomena like the El Nino Sothern Oscillation (ENSO), which can be the cause of major impacts, could change these results, but we leave this to future research once the GCMs are improved in this respect.

Open Access This article is distributed under the terms of the Creative Commons Attribution License which permits any use, distribution, and reproduction in any medium, provided the original author(s) and the source are credited.

\section{References}

Allen R, Pereira L, Raes D, (1998) Crop evapotranspiration-guidelines for computing crop water requirementsFAO irrigation and drainage, Paper 56. FAO

Arndt C, Strzepeck K, Tarp F, Thurlow J, Fant C, Wright L (2010) Adapting to climate change: an integrated biophysical and economic assessment for Mozambique. Sustain Sci 6(1):7-20

Arndt C, Fant C, Robinson S, Strzepek K (2014) Informed selection of future climates. Climatic Change. In Review

Arnell, N.W., (1999) Climate change and global water resources. Glob Environ Chang 9:S31-S50. Ayalew, M., 1997: What is food security and famine and hunger? Internet Journal for African Studies, 2. Available online at http://www.brad.ac.uk/research/ijas/ijasno2/ayalew.html

Arora VK, Boer GJ (2001) Effects of simulated climate change on the hydrology of major rivers basins. J Geophys Res 106(D4):3335-3348

Blöschl G, Ardoin-Bardin S, Bonell M, Dorninger M, Goodrich D, Gutknecht D, Matamoros D, Merz B, Shand P, Szolgay J (2007) At what scales do climate variability and land cover change impact on flooding and low flows? Hydrol Process 21:1241-1247

Brown C, Wilby RL (2012) An alternate approach to assessing climate risks, Eos. Trans Am Geophys Union 93(41):401-402. doi:10.1029/2012EO410001

Collier P, Conway G, Venables T (2008) Climate change and Africa. Oxf Rev Econ Policy 24(2):337-353

de Wit M, Stankiewicz J (2006) Changes in surface water supply across africa with predicted climate change. Science 311:1917. doi:10.1126/science.1119929

Dessai S, Hulme M (2007) Assessing the robustness of adaptation decisions to climate change uncertainties: A case study on water resources management in the East of England. Glob Environ Chang 17(1):59-72. doi: 10.1016/j.gloenvcha.2006.11.005

Droogers P, \& Allen RG (2002) Estimating reference evapotranspiration under inaccurate data conditions. Irrig Drain Syst 16:33-45

Fant C, Gueneau A, Strzepek K, Awadalla S, Farmer W, Blanc E, Schlosser CA (2012) CliCrop: A crop waterstress and irrigation demand model for an integrated global assessment modeling approach. Joint Program on the Science and Policy of Global Change, Report 214. MIT. http://globalchange.mit.edu/research/ publications $/ 2264$

Farmer W, Strzepek K, Schlosser CA, Droogers P, Gao X (2011) DSpace@MIT : A method for calculating reference evapotranspiration on daily time scales. MIT Joint Program on the Science and Policy of Global Change. MIT

Gupta V, Sorooshian S (1983) Uniqueness and observability of conceptual rainfall-runoff model parameters: the percolation process examined. Water Resour Res 19(1):269-276. doi:10.1029/WR019i001p00269

Gupta V, Sorooshian S (1985) The relationship between data and the precision of parameter estimates of hydrologic models. J Hydrol 81:57-77 
Haasnoot M, Middelkoop H (2012) A history of futures: a review of scenario use in water policy studies in the Netherlands. Environ Sci Pol 19-20:108-120. doi:10.1016/j.envsci.2012.03.002

Haasnoot M, Kwakkel JH, Walker WE, ter Maat J (2013) Dynamic adaptive policy pathways: a method for crafting robust decisions for a deeply uncertain world. Glob Environ Chang 23(2):485-498. doi:10.1016/j. gloenvcha.2012.12.006

Hassan RM (2010) Implications of climate change for agricultural sector performance in Africa: policy challenges and research agenda. J Afr Econ 19(suppl 2):ii77-ii105. doi:10.1093/jae/ejp026

Immerzeel W (2008) Historical trends and future predictions of climate variability in the Brahmaputra basin. Int J Climatol 28(2):243-254

IPCC (2001) Climate change 2001: impacts, adaptation and vulnerability, Contribution of Working Group II to the Third Assessment Report of the Intergovernmental Panel on Climate Change. In: McCarthy JJ, Canziani OF, Leary NA, Dokken DJ and White KS (eds). Cambridge University Press, Cambridge, UK, and New York, USA, 2001. No. of pages: 1032

IPCC (2007) Contribution of Working Group II to the Fourth Assessment Report of the Intergovernmental Panel on Climate Change. In: Parry ML, Canziani OF, Palutikof JP, van der Linden PJ and Hanson CE (eds) Cambridge University Press, Cambridge, United Kingdom and New York, NY, USA

Kaczmarek Z (1993) Water balance model for climate impact analysis. ACTA Geophys Pol 41(4):1-16

Kashaigili J, McCartney M, Mahoo H (2006) Modeling the hydrology of the Usangu Plains Wetlands for environmental management, IWMI Research Report 104. Water Management

Kurukulasuriya P, Mendelsohn R, Hassan R, Benhin J, Deressa T, Diop M, Eid HM, Fosu KY, Gbetibouo G, Jain S, Mahamadou A, Mano R, Kabubo-Mariara J, El-Marsafawy S, Molua E, Ouda S, Ouedraogo M, Sene I, Maddison D, Seo SN, Dinar A (2006) Will African agriculture survive climate change? World Bank Econ Rev 20(3):367-388

Kwadijk JCJ, Haasnoot M, Mulder JPM, Hoogvliet MMC, Jeuken ABM, van der Krogt RAA, van Oostrom NGC, Schelfhout HA, van Velzen EH, van Waveren H, de Wit MJM (2010) Using adaptation tipping points to prepare for climate change and sea level rise: a case study in the Netherlands. WIREs Clim Chang 1(5): 729-740. doi:10.1002/wcc.64

Liu JJ, Folberth CC, Yang HH, Röckström JJ, Abbaspour KK, Zehnder AJBA (2013) A global and spatially explicit assessment of climate change impacts on crop production and consumptive water use. PLoS One 8(2):e57750-e57750

Lobell DB, Burke MB, Tebaldi C, Mastrandrea MD, Falcon WP, Naylor RL (2008) Prioritizing climate change adaptation needs for food security in 2030. Science 319(5863):607-610. doi:10.1126/science.1152339

Mazvimavi D, Wolski P (2006) Long-term variations of annual flows of the Okavango and Zambezi Rivers. Phys Chem Earth 31(15-16):944-951

Mitchell T, Jones P (2005) An improved method of constructing a database of monthly climate observations and associated high-resolution grids. Int J Climatol 25:693-712

Neitsch S, Arnold J, Kiniry J (2005) Soil and water assessment tool theoretical documentation: version 2005. Model Description. Soil and Water Research Laboratory

Prudhomme C, Wilby RL, Crooks S, Kay AL, Reynard NS (2010) Scenario-neutral approach to climate change impact studies: application to flood risk. J Hydrol 390(3-4):198-209

Reilly J, Paltsev S, Strzepek K, Selin NE, Cai Y, Nam K-M, Monier E, Dutkiewicz S, Scott J, Webster M and Sokolov A (2012) Valuing climate impacts in integrated assessment models: The MIT IGSM. MIT Joint Program Report Series, Report 219

Rosenzweig C, Iglesias A (1998) The use of crop models for international climate change impact assessment. In: Tsuji GY, Hoogenboom G, Thornton PK (eds) Understanding options for agricultural production. Kluwer Academic Publishers, Dordrecht, pp 267-292

Schlosser CA, Strzepek, K (2014) Regional Climate Change of the Greater Zambezi River Basin: A Hybrid Assessment. Climatic Change. In Review

Schlosser CA, Gao X, Strzepek K, Sokolov A, Forest CE, Awadalla S, Farmer W (2013) Quantifying the likelihood of regional climate change: a hybridized approach. J Climate 26(10):3394-3414

Sheffield J, Goteti G, Wood EF (2006) Development of a 50-year high-resolution global dataset of meteorological forcings for land surface modeling. J Climate 19:3088-3111

Sieber J, Purkey D (2007) User Guide for WEAP21. Stockholm Environment Institute

Smith M (1992) CROPWAT: A Computer Program for Irrigation Planning and Management: FAO Irrigation and Drainage Paper 46. ISSN 0254-5284

Strzepek K, McCluskey A, Boehlert B, Jacobsen M, Fant C (2011) Climate variability and change : a basin scale indicator approach to understanding the risk to water resources development and management. Water papers. Washington, DC: World Bank. http://documents.worldbank.org/curated/en/2011/09/15897484/climatevariability-change-basin-scale-indicator-approach-understanding-risk-water-resources-developmentmanagement 
Sutcliffe JV, Parks YP (1987) Hydrological modelling of the Sudd and Jonglei Canal. Hydrol Sci J 32:143-159

USBR [US Department of the Interior, Bureau of Reclamation] (1993) Drainage manual: a water resources technical publication. US Department of the Interior, Washington DC

Wahaj R, Maraux F (2007) Actual crop water use in project countries: a synthesis at the regional level. World Bank, Washington DC

Webster M, Sokolov AP, Reilly JM, Forest CE, Paltsev S, Schlosser CA, Wang C, Kicklighter DW, Sarofim M, Melillo J, Prinn RJ, Jacoby HD (2012) Analysis of climate policy targets under uncertainty. Clim Change 112(3-4):569-583

Wilby RL, Keenan R (2012) Adapting to flood risk under climate change. Prog Phys Geogr 36(3):348-378. doi: $10.1177 / 0309133312438908$

Wilks DS (1992) Adapting stochastic weather generation algorithms for climate change studies. Clim Change 22(1):67-84

World Bank (2009) The cost to developing countries of adapting to climate change: new methods and estimates. The Global Report of the Economics of Adaption to Climate Change Study, World Bank, Washington, DC http://siteresources.worldbank.org/EXTCC/Resources/EACC-june2010.pdf

World Bank (2010) The Zambezi River Basin: a multi-sector investment opportunities analysis, Volume 1, Summary Report. World Bank, Washington DC. http://siteresources.worldbank.org/INTAFRICA/ Resources/Zambezi_MSIOA___Vol_1___Summary_Report.pdf

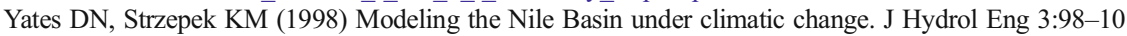

